\title{
Oxide Reduction in Advanced Metal Stacks for Microelectronic Applications
}

Wentao Qin, Alex A. Volinsky ${ }^{1}$, Dennis Werho, N. David Theodore

DigitalDNA ${ }^{\mathrm{TM}}$ Labs, Motorola Inc., Tempe, AZ 85284, USA

${ }^{1}$ Department of Mechanical Engineering, University of South Florida

\section{ABSTRACT:}

Aluminum and copper are widely used for microelectronic interconnect applications. Interfacial oxides can cause device performance degradation and failure by significantly increasing electrical resistance. Interfacial oxide layers found in $\mathrm{Al} / \mathrm{Ta}$ and $\mathrm{Ta} / \mathrm{Cu}$ metal stacks were studied using Transmission Electron Microscopy (TEM) combined with Energy Dispersive Spectroscopy (EDS) and Parallel Electron Energy Loss Spectroscopy (PEELS). The analysis indicates that the observed interfacial oxide layers, $\mathrm{Al}_{2} \mathrm{O}_{3}$ and mainly $\mathrm{Ta}_{2} \mathrm{O}_{5}$, result from spontaneous reductions of $\mathrm{Ta}$ oxide and $\mathrm{Cu}$ oxide, respectively. Thermodynamics enables interpretation of the results.

\section{INTRODUCTION:}

Advanced metallization schemes are commonly used for microelectronic manufacturing. For high-performance integrated circuits, the semiconductor industry has made a switch from $\mathrm{Al} / \mathrm{SiO}_{2}$ to $\mathrm{Cu} /$ low-k dielectric metallization; however, lower performance chips still utilize $\mathrm{Al}$ metallization, and some applications use both $\mathrm{Cu}$ and $\mathrm{Al}$ in the same chip. For instance, $\mathrm{Al}$ can be used to make a process compatible with previously existing wire-bonding and packaging schemes. It can also be used for metallization of top layers to protect the underlying $\mathrm{Cu}$ from oxidation.

In the metallization process, oxidation of individual film surface can lead to further reactions and will ultimately affect physical properties of the stack, such as the electrical conductivity, wettability, and adhesion. Some of the effects are beneficial to the device performance, while others are detrimental. It is therefore important to understand, control and utilize such oxidation.

Concerning the oxidations of $\mathrm{Al}, \mathrm{Ti}$ and $\mathrm{Si}$, both $\mathrm{Al}$ and $\mathrm{Ti}$ have a higher affinity for oxygen than $\mathrm{Si}$ does. As a result, when either $\mathrm{Al}$ or Ti is deposited on $\mathrm{SiO}_{2}$, it can reduce the underlying $\mathrm{SiO}_{2}$ [1-6]. A similar behavior has been reported for metal, metal-oxide interfaces in powders [7].

Reduction of surface oxides has been found to correlate with wettability, and eventually the enhancement of adhesion in different metal-oxide systems [8,9]. For instance, metals with higher oxygen affinity showed higher wettabilities in the case of metal-TiO interfaces [10]. This eventually resulted in an improved adhesion. In Ti/GaAs and Ti/Si systems, the presence of high oxygen concentrations has been found to result in increased adhesion [11].

This paper reports analyses of interfacial oxides in $\mathrm{Al} / \mathrm{Ta}$ and $\mathrm{Ta} / \mathrm{Cu}$ stacks, discussions of the corresponding oxide reductions and process modifications. The physical property of concern is the electrical conductivities of the stacks. 


\section{EXPERIMENTAL DETAILS:}

The metal film-stacks were deposited on Si wafers. In the case of the Al/Ta stack, the Ta deposition was followed by that of Al. Surface of the Ta layer was exposed to the air during transfer of the wafer to a different tool for the deposition of $\mathrm{Al}$, and there was no surface clean prior to the $\mathrm{Al}$ deposition.

For the $\mathrm{Ta} / \mathrm{Cu}$ stack, a $\mathrm{Cu}$ film was photolithographically patterned, and the photoresist used for patterning was then stripped in an ashing process. The process resulted in an oxidation of the exposed $\mathrm{Cu}$ surface. Prior to Ta deposition, a RF sputter clean was used to remove the surface $\mathrm{Cu}$ oxide. The $\mathrm{RF}$ sputter is equivalent to the process used to remove $10 \mathrm{~nm}$ of $\mathrm{SiO}_{2}$.

Cross-section TEM analyses were used to investigate the $\mathrm{Al} / \mathrm{Ta}$ and $\mathrm{Ta} / \mathrm{Cu}$ interfaces in the stacks. A focused ion-beam (FIB) pre-thin method was used to prepare the TEM samples. A $3 \mathrm{~mm}$ wide and 10 micron thick slice was prepared using mechanical grinding. FIB was then used to thin the area of interest down to electron translucency. Imaging was performed using parallel illumination. Energy-dispersive spectrometry (EDS) and parallel electron energy-loss spectrometry (PEELS) were used for elemental analysis. Analyses were performed using an electron-beam focused to a $\sim 1 \mathrm{~nm}$ fine probe. A field-emission gun TEM was used, operating at an accelerating voltage of $200 \mathrm{kV}$.

\section{A. Reduction of Ta oxide by Al}

A high-resolution TEM micrograph, obtained from the Al/Ta stack, is shown in Fig. 1. The micrograph reveals the presence of a 3-5 $\mathrm{nm}$ amorphous layer between Ta and Al.

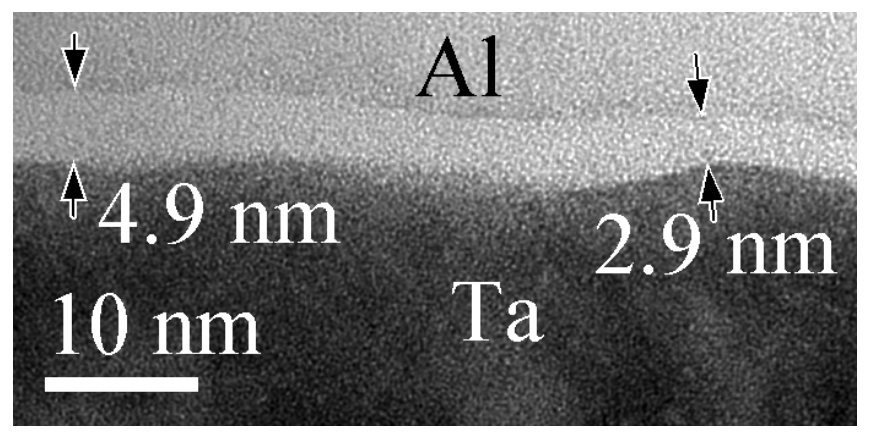

Figure 1. High-resolution TEM micrograph obtained from the Ta/Al stack. An amorphous layer of a low mass-density between $\mathrm{Al}$ and Ta is visible.

Figure 2 presents EDS spectra, one obtained from the Al layer, and the other from the amorphous interfacial layer. $\mathrm{Al}$ and $\mathrm{O}$ peaks are evident. The $\mathrm{Si} \mathrm{K}_{\alpha}$ peak arose from Si re-deposited on the area of interest during TEM sample preparation, as well as fluorescence of the Si substrate and $\mathrm{SiO}_{2}$ as the interlayer dielectric material present in the sample. After subtractions of the $\mathrm{O} \mathrm{K}_{\alpha}$ components from background (mainly excitations by Bremsstrahlung X-rays and un-collimated electrons) and re-deposition, and $\mathrm{Al} \mathrm{K}_{\alpha}$ components from background, the interfacial layer is calculated to contain 40 at. $\% \mathrm{Al}$ and 60 at. \% oxygen, using the ratio method and thin-film criterion $[12,13]$. The oxide is therefore inferred to be $\mathrm{Al}_{2} \mathrm{O}_{3}$. 


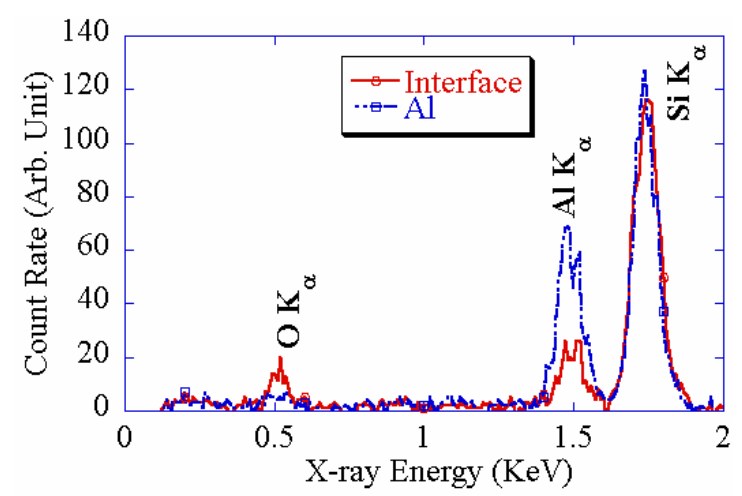

Figure 2. EDS spectra from Al layer and from interfacial layer between Al and Ta. The Si peak arose from $\mathrm{Si}$ re-deposited on the area of interest during TEM sample preparation, as well as fluorescence of the $\mathrm{Si}$ substrate and $\mathrm{SiO}_{2}$ as the interlayer dielectric material present in the sample.

The surface of the Ta was oxidized during exposure to air. The native surface oxide on Ta has been characterized by XPS [14] as being $\sim 85 \% \mathrm{Ta}_{2} \mathrm{O}_{5}$ with the remainder possibly being $\mathrm{Ta}_{2} \mathrm{O}$ and $\mathrm{Ta}_{2} \mathrm{O}_{3}$ [15] or $\mathrm{TaO}$ and $\mathrm{TaO}_{2}$ [16]. In the present study, $\mathrm{Al}$ was deposited on the oxidized Ta surface. Al could reduce this surface oxide based on the following reaction [17]:

$$
10 \mathrm{Al}+3 \mathrm{Ta}_{2} \mathrm{O}_{5} \rightarrow 5 \mathrm{Al}_{2} \mathrm{O}_{3}+6 \mathrm{Ta}, \Delta \mathrm{F}=-489 \mathrm{~K} \mathrm{Cal} / \mathrm{Mole} \text { at } 25^{\circ} \mathrm{C}
$$

The free energy of this reaction is negative, indicating that the reaction is thermodynamically favorable. The presence of oxide, whether Ta based or Al based, will increase the electrical resistance of the metal stack.

\section{B. Reduction of Cu oxide by Ta}

The interface in the $\mathrm{Ta} / \mathrm{Cu}$ stack was next investigated. Patterning and etching, used for wafer fabrication, resulted in an oxidized $\mathrm{Cu}$ surface. The oxidation occurred during an ash step to strip the photoresist. An RF sputter was used to clean the $\mathrm{Cu}$ surface prior to the Ta deposition. The sputter was equivalent to a process to remove $10 \mathrm{~nm}$ of $\mathrm{SiO}_{2}$. The TEM image in Fig. 3a shows a 3-4nm interfacial layer.

The interfacial layer was investigated using EDS and PEELS spectral profiling in scanning TEM mode. Integrated intensity of $\mathrm{Ta}_{\alpha} \mathrm{X}$-ray peaks is shown in Fig. $3 \mathrm{~b}$. The following formula was used to calculate the areal densities of $\mathrm{Cu}$ and $\mathrm{O}$ [18]:

$$
N=\frac{I_{k}(\beta, \Delta)}{I(\beta, \Delta) \cdot \sigma_{k}(\beta, \Delta)}
$$

In the expression above, $\mathrm{N}$ is the areal density, $\beta$ is the collection angle, $\Delta$ is the energy range over which integration of electron intensity is performed, $I_{k}(\beta, \Delta)$ is core-loss integral including 

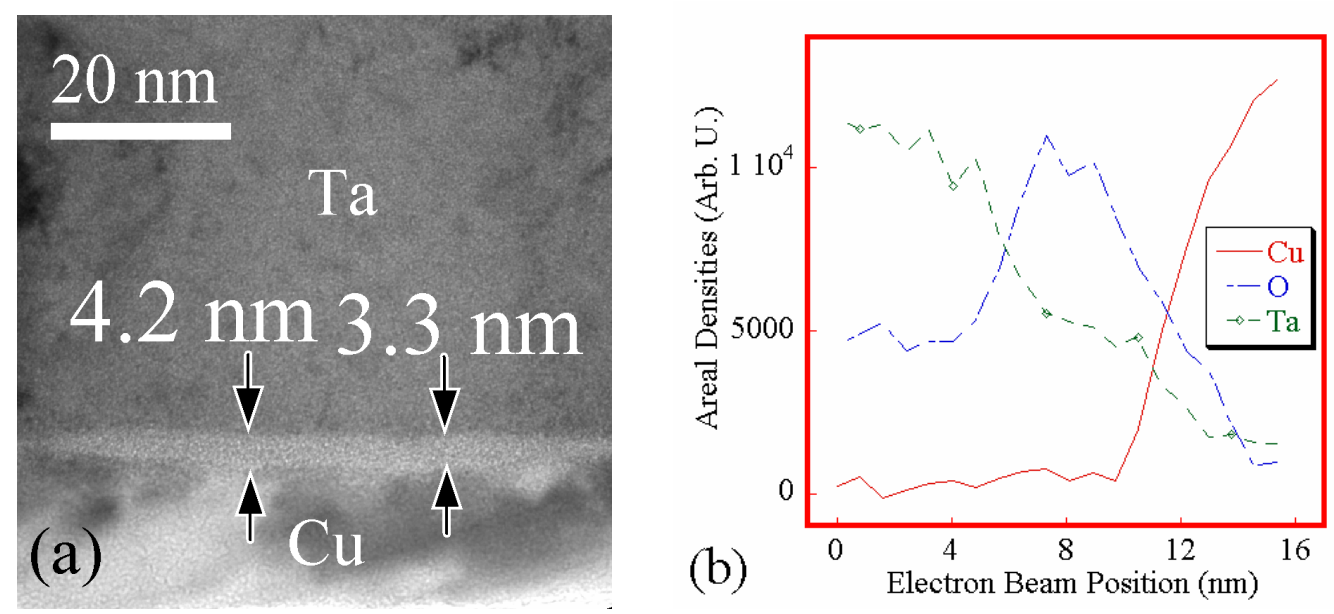

Figure 3. (a) High-resolution TEM micrograph obtained from the Ta/Cu stack. A 3-5 nm amorphous interfacial layer is visible. (b) Ta, $\mathrm{Cu}, \mathrm{O}$ areal-density profiles from integrated intensities of $\mathrm{Ta}_{\alpha} \mathrm{X}$-ray, $\mathrm{Cu} \mathrm{L}_{2,3}$ ionization edge and $\mathrm{O} \mathrm{K}$ ionization edge.

plural scattering, $\mathrm{I}(\beta, \Delta)$ is the low-loss integral, and $\sigma_{\mathrm{k}}(\beta, \Delta)$ is a partial ionization cross-section for energy losses within $\Delta$ of the ionization threshold.

No $\mathrm{Cu} \mathrm{L}_{2,3}$ edge was detected when the electron beam was positioned within the interfacial layer [19]. PEELS spectra from the interfacial layer, and from the $\mathrm{Cu}$ layer, are shown in Fig. 4a. Fig. 4b shows an EDS spectrum obtained from the interfacial layer. Standardless EDS quantification shows 65 at. $\% \mathrm{O}$ and 35 at. \% Ta. Native oxides on Ta have been found to be predominantly $\mathrm{Ta}_{2} \mathrm{O}_{5}$ with other sub-oxides [20]. Among the possible Ta oxides $\left(\mathrm{Ta}_{2} \mathrm{O}_{5}, \mathrm{TaO}_{2}, \mathrm{TaO}\right), \mathrm{Ta}_{2} \mathrm{O}_{5}$ is the most stable, and difficult to reduce [20]. Based on this information and our experimental data, it is reasonable to infer that the surface $\mathrm{Cu}$ oxide was reduced spontaneously by the Ta. Two reduction reactions are possible, based on the free energies of formation [17]:
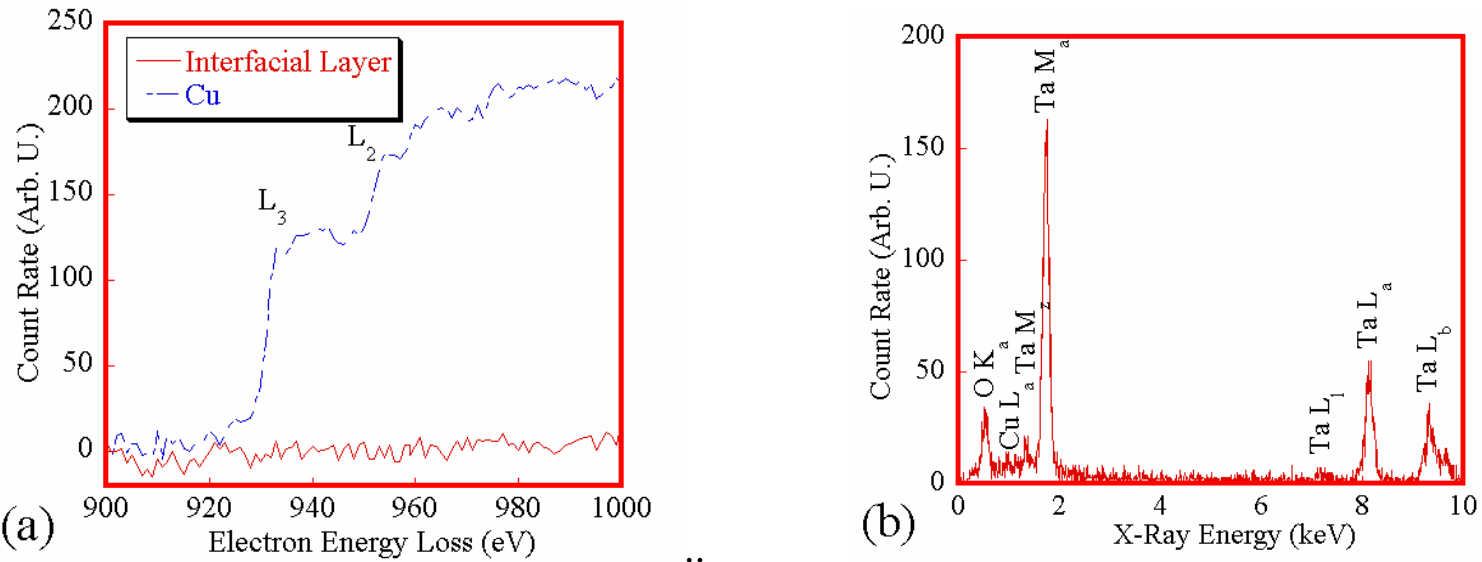

Figure 4. (a) Electron energy-loss spectra from $\mathrm{Cu}$ metal layer and $\mathrm{Ta}-\mathrm{Cu}$ interfacial-oxide layer. (b) EDS spectrum from $\mathrm{Ta}-\mathrm{Cu}$ interfacial-oxide layer. 

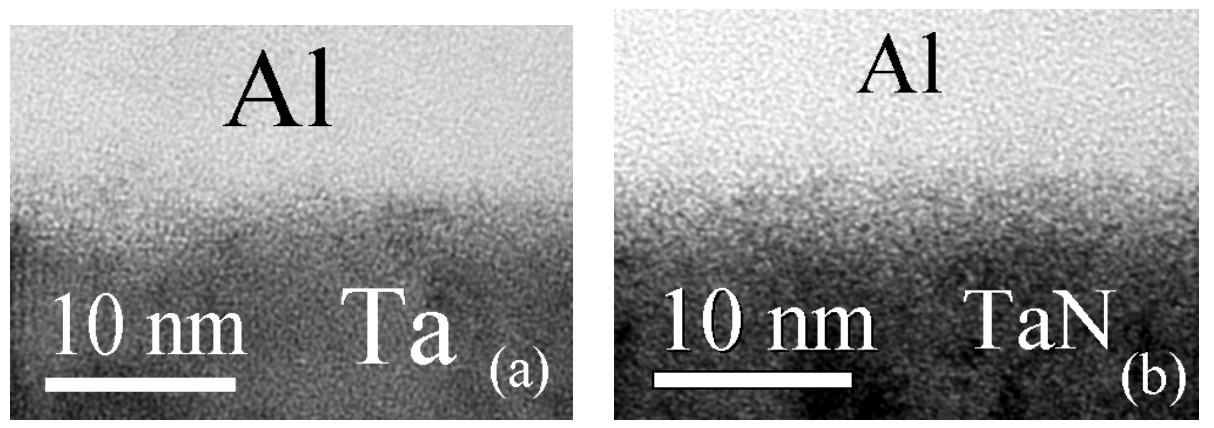

Figure 5. High resolution TEM images of the Al/Ta interface processed with a pre-Al RF sputter removal of the Ta surface oxide (a), and the Al/TaN interface which was not exposed to the air between the depositions of TaN and $\mathrm{Al}(\mathrm{b})$.

$$
\begin{gathered}
2 \mathrm{Ta}+5 \mathrm{Cu}_{2} \mathrm{O} \rightarrow \mathrm{Ta}_{2} \mathrm{O}_{5}+10 \mathrm{Cu}, \Delta \mathrm{F}=-272 \mathrm{~K} \mathrm{Cal} / \mathrm{Mole} \text { at } 25^{\circ} \mathrm{C} \\
2 \mathrm{Ta}+5 \mathrm{CuO} \rightarrow \mathrm{Ta}_{2} \mathrm{O}_{5}+5 \mathrm{Cu}, \Delta \mathrm{F}=-120 \mathrm{~K} \mathrm{Cal} / \mathrm{Mole} \text { at } 25^{\circ} \mathrm{C}
\end{gathered}
$$

Other reactions resulting in Ta sub-oxides were not evaluated due to the unavailability of relevant free-energies in the literature.

\section{Process Optimization}

The analytical results presented above showed interfacial oxides responsible for increased electrical resistance of metal stacks. A few possible solutions were evaluated to reduce the resistance to acceptable values. In one case, the Ta-surface oxide was removed using a RF sputter-clean prior to Al deposition. A second solution involved replacing the Ta with TaN, deposited in the same chamber as the Al, without an intervening air-exposure. No interfacial oxide was found in either case as shown in the high-resolution TEM images presented in Fig. 5. Electrical testing of via chains using these modified processes showed a 10x reduction in resistance.

\section{CONCLUSIONS}

High resistances were found in metallization stacks containing thin films of $\mathrm{Al} / \mathrm{Ta}$, and $\mathrm{Ta} / \mathrm{Cu}$. The presence of interfacial oxide layers was responsible for the high resistances. The interfacial oxides resulted from air exposure between depositions of $\mathrm{Al}$ and $\mathrm{Ta}$ in the $\mathrm{Al} / \mathrm{Ta}$ stack, and from an ash used to remove photoresist in the $\mathrm{Ta} / \mathrm{Cu}$ stack. The surface oxides became interfacial oxides upon deposition of metal over-layers. Ta surface oxide was reduced by the overlying Al, and $\mathrm{Cu}$ surface oxide by the overlying Ta. The oxide layers were analyzed using PEELS and EDS in TEM. Metallization resistances were reduced to acceptable values by removing the Taoxide using a pre-Al sputter. Replacing Ta with TaN, deposited in the same chamber without air exposure, resulted in a similar drop in metallization resistance. 


\section{ACKNOWLEDGEMENTS}

The authors would like to thank Susan Williamson and Lorraine Johnston for TEM sample preparation, and Mark DeHerrera and Brian Butcher for deposition of the metal layers.

\section{REFERENCES}

1. C. R. M. Grovenor, Microelectronic Materials (IOP Publishing, Philadelphia, PA, 1989) p. 239.

2. S. P. Murarka, M. C. Peckerar, Electronic Materials: Science and Technology (Academic Press, San Diego, CA, 1989) p. 284.

3. L. M. Koschier, S. R. Wenham, in Record of the Twenty-Eighth IEEE Photovoltaic Specialists Conference - 2000 (IEEE - Piscataway, NJ, USA, 2000), p. 407.

4. M. A. Taubenblatt and C.R. Helms, J. Appl. Phys. 53(9) 6308(1982).

5. M. Liehr, F. K. LeGoues, G. W. Rubloff, P. S. Ho, J. Vac. Sci. Technol. A 3 (3) 983 (1985).

6. T. Ohwaki, K. Aoki, T. Yoshida, S. Hashimoto, Y. Mitsushima, Y. Taha, Surface Science, 496, 433 (1999).

7. Ch. Laurent, Ch. Blaszczyk, M. Brieu, A. Rousset, Nanostructured Materials 6 317(1995).

8. Yu. V. Naidich, Prog. Surf. Membrane Sci., 14, 353 (1981).

9. D. M. Lipkin, J. N. Israelachvili, and D. R. Clarke, Philosophical Magazine A, 76, 715 (1997).

10. U. Diebold, J-M Pan, and T. E. Madey, Surf. Sci., 333, 845 (1995).

11. A. A. Volinsky, "A Comparison Study of Ti/GaAs Ti/Si Fracture, Mechanics of Thin Films and Other Small Structures Symposium", presented at the 14th U.S. National Congress of Theoretical and Applied Mechanics, Blacksburg, Virginia, (2002) (unplublished).

12. G. Cliff, and G. Lorimore, Journal of Microscopy, 103203 (1975).

13. D. Joy in Principles of Analytical Electron Microscopy, edited by D. Joy, A. Romig, Jr., and J. Goldstein (Plenum Press, New York and London, 1986), p. 155.

14. B. Vincent Crist in Monochromatic XPS Spectra: The Elements and Native Oxides, (Wiley, Chichester, England, 2000) p. 478.

15. Himpsel, et al., Phys. Rev. B, 30 (12), 7236 (1984).

16. N. N. Greenwood \& A. Earnshaw in Chemistry of the Elements (Butterworth-Heinemann, Oxford, 1997), p. 981.

17. L. F. Epstein in Ceramic Age, (April 1954) 37.

18. R. Egerton in Electron Energy-Loss Spectroscopy in the Electron Microscope (Plenum Press, New York and London, 1996), p. 280.

19. C. Ahn and O. Krinavek, in EELS Atlas (1983). 